\title{
Toxicidade de Herbicidas Utilizados na Cultura da Cana-de- AÇÚCAR À BACTÉRIA Diazotrófica Azospirillum brasilense
}

\author{
Toxicity of Herbicides Applied on Sugarcane to the Diazotrophic Bacterium \\ Azospirillum brasilense
}

\author{
PROCÓPIO, S.O. ${ }^{2}$, FERNANDES, M.F. ${ }^{2}$,TELES, D.A. ${ }^{3}$, SENA FILHO, J.G. ${ }^{2}$, \\ CARGNELUTTI FILHO, A. ${ }^{4}$, VARGAS, L. ${ }^{5}$ e SANT'ANNA, S.A.C. ${ }^{6}$
}

\begin{abstract}
RESUMO - Objetivou-se neste trabalho identificar herbicidas utilizados na cultura da canade-açúcar que não alteram o crescimento ou a capacidade de fixação biológica de nitrogênio (FBN) da bactéria diazotrófica Azospirillum brasilense. Dezoito herbicidas - paraquat, ametryn, amicarbazone, diuron, metribuzin, [hexazinone + diuron], [hexazinone + clomazone], clomazone, isoxaflutole, sulfentrazone, oxyfluorfen, imazapic, imazapyr, [trifloxysulfuronsodium + ametryn], S-metolachlor, glyphosate, MSMA e 2,4-D - foram testados em suas doses comerciais quanto ao impacto sobre o crescimento da bactéria em meio liquido DIGs. As variáveis capacidade de suporte de crescimento (carrying capacity) do meio de cultura, duração da fase lag e tempo de geração de A. brasilense foram calculadas a partir de dados de densidade ótica obtidos, em intervalos regulares, durante a incubação de culturas por $55 \mathrm{~h}$. O impacto dos herbicidas na atividade da nitrogenase de $A$. brasilense foi avaliado em meio semissólido $\mathrm{NFb}$, sem $\mathrm{N}$, pela técnica da atividade de redução do acetileno (ARA). Os efeitos dos herbicidas sobre as variáveis de crescimento e ARA foram comparados ao controle pelo teste de Dunnett. Paraquat, oxyfluorfen, [trifloxysulfuron-sodium + ametryn] e glyphosate reduziram a capacidade do meio DIGs em suportar o crescimento de A. brasilense. Esse efeito foi associado ao aumento da duração da fase lag e do tempo de geração para [trifloxysulfuron-sodium + ametryn] e ao aumento no tempo de geração para glyphosate. MSMA, paraquat e amicarbazone reduzem a FBN in vitro de $A$. brasilense, porém essa redução é mais severa na presença do paraquat. Os demais herbicidas não alteram o crescimento e a FBN de $A$. brasilense.
\end{abstract}

Palavras-chave: Saccharum spp., fixação biológica de nitrogênio, pesticidas.

\begin{abstract}
The objective of this work was to identify the herbicides applied on sugarcane that do not affect the growth nor the process of biological nitrogen fixation (BNF) of the diazotrophic bacterium Azospirillum brasilense. Commercial doses of eighteen herbicides (paraquat, ametryn, amicarbazone, diuron, metribuzin [hexazinone + diuron] [hexazinone + clomazone] clomazone, isoxaflutole, sulfentrazone, oxyfluorfen, imazapic, imazapyr, [trifloxysulfuron-sodium + ametryn], S-metolachlor, glyphosate, MSMA and 2,4-D) were tested regarding their impact on the bacterial growth in liquid DIG medium. Thus, the carrying capacity of the culture medium, duration of lag phase and generation time of $\boldsymbol{A}$. brasilense were determined by calculating the optical density data obtained at regular intervals during the incubation of the cultures for $55 \mathrm{~h}$. The impact of herbicides on nitrogenase activity of $\boldsymbol{A}$. brasilense was evaluated in semi-solid $N$-free NFB medium by acetylene reduction assay (ARA). The effects of herbicides on the growth variables and ARA were compared with the control by the Dunnett test. Paraquat, oxyfluorfen, [trifloxysulfuron-sodium + ametryn] and glyphosate reduced the carrying capacity of DIG medium with respect to $\boldsymbol{A}$. brasilense growth. This effect was associated with increases in both the length of the lag phase and generation time for [trifloxysulfuron-sodium + ametryn], and with the increase in generation time for glyphosate. MSMA,
\end{abstract}

1 Recebido para publicação em 27.12.2010 e aprovado em 2.8.2011.

2 Pesquisador da Embrapa Tabuleiros Costeiros, 49025-040 Aracaju-SE, <procopio@ cpatc.embrapa.br>; ${ }^{3}$ Discente do Programa de Pós-Graduação em Biotecnologia, Universidade Federal de Sergipe - UFS, 49100-000 São Cristovão-SE; ${ }^{4}$ Professor do Dep. de Fitotecnia, Universidade Federal de Santa Maria - UFSM, 97105-900 Santa Maria-RS; ${ }^{5}$ Pesquisador da Embrapa Trigo, 99001-970 Passo Fundo-RS; ${ }^{6}$ Discente do Programa de Pós-Graduação em Agronomia - Ciência do Solo, Universidade Federal Rural do Rio de Janeiro - UFRRJ, 23890-000 Seropédica-RJ. 
paraquat and amicarbazone reduce the BNF of $\boldsymbol{A}$. brasilense; however, this reduction is more severe in the presence of paraquat. The other herbicides do not affect the growth or the BNF of A. brasilense.

Key words: Saccharum spp., biological nitrogen fixation, pesticides.

\section{INTRODUÇÃO}

A cultura da cana-de-açúcar exerce papel de grande importância na economia de diversos países dos cinco continentes, sendo de maior destaque nas economias da América Latina e do Caribe (Coelho et al., 2003). No Brasil, é cultivada em quase todas as suas regiões agrícolas (Baldani et al., 2002). Atualmente, estima-se que a cultura da canade-açúcar esteja presente em mais de nove milhões de hectares das áreas agrícolas brasileiras (IBGE, 2011).

Além da crescente demanda externa, o requerimento de etanol para abastecimento do mercado interno tem sido crescente durante toda a década, sobretudo após 2003, com o início da comercialização de carros com motor flex no Brasil (Rudorff et al., 2010). Para suprir essas demandas, novas unidades industriais estão sendo construídas em várias regiões do País, aumentando muito a área cultivada com cana-de-açúcar (Nassar et al., 2008; Rudorff et al., 2010). Nesse aspecto, uma das principais preocupações do governo brasileiro é que essa expansão ocorra em regiões apropriadas, referendadas por um zoneamento agrícola, impedindo o avanço da cultura nos biomas amazônico e pantanal. Essa expansão significativa e inevitável da cultura, aliada à preocupação cada vez maior de determinados setores da sociedade com a sustentabilidade dos agroecossistemas, gera uma demanda tecnológica pelo desenvolvimento de sistemas de produção mais eficientes e preservacionistas.

A cana-de-açúcar é uma cultura que extrai expressiva quantidade de nitrogênio $(\mathrm{N})$; para alcançar produtividade média de $100 \mathrm{Mg}^{\text {ha }}{ }^{-1}$ de colmos, acumula em sua parte aérea 180-250 e 120-180 kg ha-1 de N, nos ciclos culturais de cana-planta (primeiro ciclo) e soqueiras (ciclos seguintes), respectivamente (Sampaio et al., 1984). Considerando-se que as quantidades de $\mathrm{N}$-fertilizante aplicadas no
Brasil não ultrapassam a dose de $80 \mathrm{~kg} \mathrm{ha}^{-1}$ de $\mathrm{N}$ em média, o restante desse nutriente pode ser proveniente do solo, o qual é naturalmente pouco disponível para as plantas na maioria dos solos tropicais e/ou da fixação biológica do $\mathrm{N}$ atmosférico (FBN) realizada por bactérias diazotróficas endofíticas ou rizosféricas (Urquiaga et al., 1992). Trabalhos indicam que esta última fonte de $\mathrm{N}$ pode contribuir com até $60 \%$ de todo o $\mathrm{N}$ acumulado pelas plantas de cana-de-açúcar (Boddey et al., 2001), variando entre os diferentes genótipos (Reis et al., 2000). Oliveira et al. (2002) verificaram que a inoculação de plantas micropropagadas de cana-de-açúcar com uma mistura de cinco estirpes de diferentes espécies de bactérias diazotróficas resultou em contribuições ao redor de $30 \%$ do $\mathrm{N}$ total absorvido.

Entre as diferentes espécies de bactérias diazotróficas associadas a gramíneas, destacam-se as do gênero Azospirillum, que, além da fixação de $\mathrm{N}$ atmosférico, também podem produzir e fornecer às plantas auxinas, giberelinas, citocininas e vitaminas (Rodelas et al., 1993; Moutia et al., 2010).

A presença de plantas daninhas em lavouras de cana-de-açúcar pode causar perdas na produtividade de colmos e de açúcar, decréscimo da longevidade do canavial, dificuldade e aumento no custo da colheita, queda na qualidade industrial da matéria-prima, servir de abrigo para pragas e doenças da cana-deaçúcar e causar depreciação no valor da terra. Entre os métodos de controle das plantas daninhas, sobressai no Brasil o químico, devido, principalmente, ao rendimento operacional e ao custo por área, comparado aos demais métodos. No entanto, a aplicação de herbicidas sobre culturas que realizam simbiose com bactérias fixadoras de $\mathrm{N}$ atmosférico pode prejudicar a eficiência na assimilação desse nutriente (Marenco et al., 1993; Novo et al., 1996, 1998; Santos et al., 2005a). Esses prejuízos devem-se à interferência do herbicida no metabolismo do microssimbionte, na planta 
hospedeira ou em ambos, quando em associação (Arruda et al., 2001). Madhaiyan et al. (2006) verificaram que o herbicida 2,4-D, adicionado na sua dose comercial ao meio de crescimento de Gluconacetobacter diazotrophicus, promoveu redução na produção de ácido 3-indol-acético (AIA) e ácido giberélico $\left(\mathrm{GA}_{3}\right)$ de 39,5 e $78,8 \%$, respectivamente, além de ocasionar a perda de 48,2 e $58,6 \%$ da habilidade da bactéria em solubilizar fósforo e zinco, respectivamente. Santos \& Flores (1995) observaram que o herbicida glyphosate ocasionou redução no tamanho das células de Azotobacter vinelandii e Azotobacter chroococcum.

Em razão desse cenário, o objetivo deste trabalho foi identificar herbicidas utilizados na cultura da cana-de-açúcar que não afetam o crescimento, ou que não causem prejuízos à capacidade de FBN da bactéria diazotrófica Azospirillum brasilense.

\section{MATERIAL E MÉTODOS}

\section{Preparo do inóculo}

A estirpe de Azospirillum brasilense (Cd) utilizada neste estudo foi obtida da Coleção de Bactérias Diazotróficas da Embrapa Agrobiologia.

As células foram ativadas em $10 \mathrm{~mL}$ de meio líquido DIGs, cuja formulação, em $\mathrm{g} \mathrm{L}^{-1}$ de água destilada, é a seguinte: glicose, 2,0; ácido málico, 2,0; peptona, 1,5; extrato de levedura, 2,0; $\mathrm{K}_{2} \mathrm{HPO}_{4}, 0,5 ; \mathrm{MgSO}_{4} \cdot 7 \mathrm{H}_{2} \mathrm{O}, 0,5 ; \mathrm{e}$ ácido glutâmico, 1,5, pH 6,8. A cultura foi incubada a $25^{\circ} \mathrm{C}$ por $72 \mathrm{~h}$, quando a densidade ótica $\left(\mathrm{DO}_{450 \mathrm{~nm}}\right)$ atingiu aproximadamente 0,6. Esse mesmo procedimento de ativação das bactérias foi usado para a preparação do inóculo em todos os ensaios descritos a seguir.

\section{Efeito de doses comerciais de herbicidas sobre o crescimento de $A$. brasilense}

Dezoito herbicidas registrados para a cultura de cana-de-açúcar no Brasil (Brasil, 2011) foram avaliados (Tabela 1) quanto ao impacto sobre o crescimento e a fixação biológica de nitrogênio de Azospirillum brasilense em condições de laboratório. Soluções-estoque dos herbicidas foram preparadas com água destilada e filtrada através de membranas Millipore ${ }^{\circledR}$ com poros de $0,22 \mu \mathrm{m}$. As concentrações dos herbicidas nas soluções-estoque foram determinadas de modo que a adição de $200 \mu \mathrm{L}$ destas ao volume final de meio de cultura utilizado nos diferentes ensaios resultasse nas concentrações previamente estabelecidas para cada tratamento.

$\mathrm{O}$ efeito de doses comerciais de herbicidas sobre os parâmetros de crescimento de A. brasilense foi avaliado pelo monitoramento do crescimento celular por turbidimetria das culturas inoculadas em meio líquido DIGs, misturados com os herbicidas e incubados por $55 \mathrm{~h}$. Para isso, um volume de $200 \mu \mathrm{L}$ das soluções herbicidas filtradas foi adicionado a erlenmeyers de $50 \mathrm{~mL}$ contendo $25 \mathrm{~mL}$ de meio liquido DIGs, de modo a atingir as concentrações comerciais recomendadas para cada produto (Tabela 1). Frascos controle receberam $200 \mu \mathrm{L}$ de água destilada filtrada através de membrana Millipore ${ }^{\circledR}$. Os frascos foram inoculados com $40 \mu \mathrm{L}$ de uma cultura de $A$. brasilense ativa $\left(\mathrm{DO}_{450 \mathrm{~nm}}=0,6\right)$. Após inoculação, os frascos foram rapidamente agitados e o conteúdo deles vertido em placas de Petri estéreis. Aliquotas de $200 \mu \mathrm{L}$ dessas misturas foram transferidas para microplacas de 96 poços, utilizando-se uma micropipeta de oito canais, de modo que cada coluna da placa (oito poços) recebesse um tratamento herbicida diferente. Uma das colunas de poços foi preenchida com meio DIGs estéril, para verificar a possivel ocorrência de contaminação da microplaca durante as leituras de DO ao longo do período dos ensaios. As placas foram incubadas a $32{ }^{\circ} \mathrm{C}$, no escuro, e as leituras de DO, realizadas em intervalos regulares (a cada $2 \mathrm{~h}$, aproximadamente) em um leitor de microplacas, ajustado no comprimento de ondas de $450 \mathrm{~nm}$. Com os resultados das leituras, foram geradas curvas de crescimento bacteriano durante o período de avaliação, para os diferentes tratamentos.

A diferença entre os valores máximos e mínimos de absorvância durante o período de incubação de cada uma das culturas (tratamentos herbicidas) foi interpretada como a capacidade de suporte de crescimento bacteriano (carrying capacity) do meio de cultura contendo os diferentes produtos. A capacidade de suporte do 
Tabela 1 - Lista de herbicidas avaliados no presente estudo

\begin{tabular}{|c|c|c|c|c|c|}
\hline Nome comum & Marca comercial & $\begin{array}{l}\text { Dose } \\
\left(\mathrm{g} \mathrm{ha}^{-1}\right)\end{array}$ & $\begin{array}{c}\text { Concentração } \\
\left(\mu \mathrm{g} \mathrm{L}^{-1}\right)\end{array}$ & Grupo químico & Mecanismo de ação \\
\hline Paraquat & Gramoxone $200^{(\mathbb{B}}$ & 600 & 8,49 & Bipiridílios & Inibidor do fotossistema I \\
\hline Ametryn & Gesapax $^{\circledR}$ & 4.000 & 56,60 & Triazinas & Inibidor do fotossistema II \\
\hline Amicarbazone & Dinamic $^{\mathbb{R}}$ & 1.400 & 19,81 & Triazolinonas & Inibidor do fotossistema II \\
\hline Diuron & Herburon $500 \mathrm{BR}^{\circledR}$ & 3.200 & 45,28 & Derivados da ureia & Inibidor do fotossistema II \\
\hline Metribuzin & Sencor $480^{\circledR}$ & 1.920 & 27,17 & Triazinonas & Inibidor do fotossistema II \\
\hline Hexazinone + diuron & Velpar K WG ${ }^{\circledR}$ & $396+1.404$ & $5,60+19,87$ & $\begin{array}{l}\text { Triazinonas }+ \\
\text { Derivados da ureia }\end{array}$ & $\begin{array}{l}\text { Inibidor do fotossistema II + } \\
\text { Inibidor do fotossistema II }\end{array}$ \\
\hline $\begin{array}{l}\text { Hexazinone }+ \\
\text { clomazone }\end{array}$ & Discover $500 \mathrm{WP}^{\circledR}$ & $250+1.000$ & $3,54+14,15$ & $\begin{array}{l}\text { Triazinonas + } \\
\text { Isoxazolidinonas }\end{array}$ & $\begin{array}{l}\text { Inibidor do fotossistema II + } \\
\text { Inibidor da biossíntese de } \\
\text { carotenoides (local de ação } \\
\text { desconhecido) }\end{array}$ \\
\hline Clomazone & $\mathrm{Gamit}^{\circledR}$ & 1.100 & 15,57 & Isoxazolidinonas & $\begin{array}{l}\text { Inibidor da biossíntese de } \\
\text { carotenoides (local de ação } \\
\text { desconhecido) }\end{array}$ \\
\hline Isoxaflutole & Provence $750 \mathrm{WG}^{\circledR}$ & 262,5 & 3,71 & Isoxazoles & $\begin{array}{l}\text { Inibidor da biossíntese de } \\
\text { carotenoides }\end{array}$ \\
\hline Sulfentrazone & Boral $500 \mathrm{SC}^{\circledR}$ & 800 & 11,32 & Triazolinonas & $\begin{array}{l}\text { Inibidor da protoporfirinogênio } \\
\text { oxidase (PPO) }\end{array}$ \\
\hline Oxyfluorfen & Goal BR ${ }^{\circledR}$ & 1.200 & 16,98 & Difeniléteres & $\begin{array}{l}\text { Inibidor da protoporfirinogênio } \\
\text { oxidase (PPO) }\end{array}$ \\
\hline Imazapic & Plateau $^{\circledR}$ & 245 & 3,47 & Imidazolinonas & $\begin{array}{l}\text { Inibidor da acetolactato sintase } \\
\text { (ALS) }\end{array}$ \\
\hline Imazapyr & Contain $^{\circledR}$ & 500 & 7,08 & Imidazolinonas & $\begin{array}{l}\text { Inibidor da acetolactato sintase } \\
\text { (ALS) }\end{array}$ \\
\hline $\begin{array}{l}\text { Trifloxysulfuron-sodium } \\
+ \text { ametryn }\end{array}$ & Krismat $^{\circledR}$ & $37+1.463$ & $0,52+20,70$ & $\begin{array}{l}\text { Sulfonilureias + } \\
\text { Triazinas }\end{array}$ & $\begin{array}{l}\text { Inibidor da acetolactato sintase } \\
\text { (ALS) + Inibidor do fotossistema II }\end{array}$ \\
\hline S-metolachlor & Dual Gold $^{\mathbb{R}}$ & 1.920 & 27,17 & Cloroacetamidas & Inibidor da divisão celular \\
\hline Glyphosate & Roundup $^{\circledR}$ & 1.800 & 25,47 & Derivados da glicina & Inibidor da EPSP sintase \\
\hline MSMA & MSMA Sanachem 720 SL $^{\circledR}$ & 2.880 & 40,75 & Organoarsenicais & Desconhecido \\
\hline 2,4-D & Aminol $806^{\circledR}$ & 1.005 & 14,22 & $\begin{array}{l}\text { Derivados do ácido } \\
\text { ariloxialcanoico }\end{array}$ & Mimetizador de auxinas \\
\hline
\end{tabular}

crescimento pelo meio DIGs em cada tratamento foi calculada para cada uma das oito repetição individualmente.

O comprimento da fase lag foi estimado como o tempo no qual o $\ln (\mathrm{DO})$ da fase lag equivaleu à média do $\ln (\mathrm{DO})$ das três primeiras leituras de DO, quando as células se encontravam indubitavelmente em fase lag. Matematicamente, o comprimento da fase lag $\left(t_{\text {lag }}\right)$ foi calculado de acordo com a seguinte equação:

$$
t_{\text {lag }}=\left[\left(\ln O D_{\text {lag }}\right)-a\right] / b
$$

em que $\ln O D_{\operatorname{lag}}$ corresponde ao ln da média das três primeiras leituras de DO; e $a$ e $b$, ao intercepto e à inclinação da equação ajustada para o ln de DO na fase log em função do tempo de incubação. Os valores de tempo de geração e $t_{\text {lag }}$ foram estimados para cada uma das oito repetições, separadamente.

O tempo de geração de $A$. brasilense exposta aos diferentes herbicidas foi calculado após transformação dos dados de DO em $\ln$ (DO). Para esses cálculos, um mínimo de cinco leituras de DO, tomadas do meio da fase $\log$, foram consideradas.

As médias de cada tratamento herbicida foram comparadas à do tratamento controle (sem herbicida) pelo teste de Dunnett $(\mathrm{p}<0,05)$.

\section{Efeito de doses comerciais de herbicidas sobre a atividade de nitrogenase de A. brasilense}

Os herbicidas foram testados quanto ao impacto na atividade da nitrogenase de 
A. brasilense quando esta foi cultivada em meio semissólido $\mathrm{NFb}$ livre de $\mathrm{N}$ (Döbereiner et al., 1995). Aliquotas de $20 \mu \mathrm{L}$ de uma cultura de $A$. brasilense crescida sob agitação por $36 \mathrm{~h}$ em meio DIGs líquido $(\mathrm{DO}=0,7)$ foram utilizadas para inocular frascos de $50 \mathrm{~mL}$ contendo $25 \mathrm{~mL}$ do meio semissólido com as diferentes concentrações de herbicidas a serem testadas. Os herbicidas foram adicionados ao meio semissólido, utilizando-se $200 \mu \mathrm{L}$ de soluções-estoque de herbicidas esterilizadas por filtração. Essas soluções foram preparadas de modo que a adição de $200 \mu \mathrm{L}$ destas a $25 \mathrm{~mL}$ de meio semissólido resultasse nas concentrações finais dos produtos determinadas para cada tratamento (Tabela 1). Nos frascos utilizados como controle, adicionaram-se $200 \mu \mathrm{L}$ de água destilada esterilizada por filtração em membrana Millipore ${ }^{\circledR}$ com poros de 0,22 $\mu \mathrm{m}$ de diâmetro. Quatro frascos foram preparados para cada tratamento. Os frascos foram fechados com tampão de algodão e incubados por $48 \mathrm{~h}$ a $32{ }^{\circ} \mathrm{C}$ no escuro. Após esse período, uma película bem desenvolvida foi observada na subsuperficie de todos os frascos controle. Cada frasco foi então fechado com um septo de borracha, sendo 10\% da atmosfera deles $(2,5 \mathrm{~mL})$ substituída por acetileno de alta pureza, por meio de uma seringa hipodérmica (Haahtela et al., 1981).

A produção de etileno foi determinada após $12 \mathrm{~h}$ de incubação a $32^{\circ} \mathrm{C}$, no escuro. Tubos sem acetileno foram também incluídos para a quantificação do etileno endógeno. Em seguida, para determinação de etileno, $100 \mu \mathrm{L}$ de amostra gasosa da atmosfera dos frascos foram injetados em um cromatógrafo a gás (Perkin-Elmer, Clarus 500) com um detector de ionização de chamas (FID) e uma coluna capilar com fase estacionária GS-CarbonPLOT (Agilent J\&W Scientific, Santa Clara, CA, USA). As temperaturas de operação da coluna, do injetor e do detector foram de $100{ }^{\circ} \mathrm{C}, 150{ }^{\circ} \mathrm{C}$ e $180{ }^{\circ} \mathrm{C}$, respectivamente. Nitrogênio de alta pureza foi utilizado como gás de arraste, com

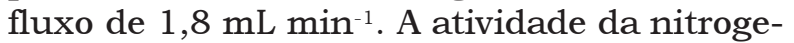
nase foi calculada em nmoles de etileno produzido por frasco por hora. Os efeitos dos herbicidas sobre a atividade de redução do acetileno (ARA) foram comparados ao do tratamento controle pelo teste de Dunnett $(p<0,05)$. As eventuais porcentagens de inibição causadas pelos herbicidas foram calculadas.

\section{Intensidade de inibição da atividade de nitrogenase por diferentes doses de herbicidas}

Os herbicidas MSMA e paraquat, cujas doses comerciais apresentaram efeitos significativos mais pronunciados sobre a atividade de nitrogenase de $A$. brasilense, foram posteriormente avaliados para determinação da concentração requerida para inibir $50 \%$ da atividade nitrogenase $\left(\mathrm{CI}_{50 \mathrm{at}}\right)$.

Os procedimentos utilizados para este ensaio foram os mesmos descritos para o ensaio anterior, exceto que cinco doses desses herbicidas foram testadas (MSMA - 0; 144,4; 433,2; 866,4; e 1.732,8 $\mathrm{g} \mathrm{ha}^{-1}$; paraquat -0, 30, 90,180 e $\left.360 \mathrm{~g} \mathrm{ha}^{-1}\right)$.

Utilizou-se análise de regressão para avaliar a resposta da atividade da nitrogenase ao incremento das doses dos herbicidas.

\section{RESULTADOS E DISCUSSÃO}

A capacidade de suporte de crescimento de A. brasilense em meio DIGs foi atingida para o tratamento controle dentro do periodo de incubação de $55 \mathrm{~h}$. Durante esse mesmo período de incubação, uma menor biomassa de $A$. brasilense foi acumulada no meio com os herbicidas paraquat, oxyfluorfen, [trifloxysulfuron-sodium + ametryn] e glyphosate (Figura 1), sendo o oposto válido para os herbicidas metribuzin, clomazone e S-metolachlor. Efeitos positivos da aplicação de herbicidas sobre o crescimento de populações de organismos diazotróficos têm sido relatados em algumas situações (Jena et al., 1990; Patnaik \& Rao, 1994; Das \& Debnath, 2006); no entanto, as causas desse beneficio ainda necessitam ser mais bem elucidadas.

Quando observada, a redução na capacidade de suporte do crescimento na presença de herbicidas pode estar associada à menor eficiência de utilização dos recursos presentes no meio pela bactéria. Em condições de estresse, parte da energia disponivel ao organismo é despendida para manter mecanismos celulares e bioquímicos de tolerância ao estressor, em detrimento do crescimento, reduzindo o coeficiente de rendimento microbiano (Schimel et al., 2007). Esse comportamento foi evidenciado no estudo de Santos et al. (2005b), 
que observaram incrementos na taxa respiratória por unidade de biomassa microbiana em resposta à adição de herbicidas ao solo, sendo essa taxa diretamente proporcional às doses aplicadas. No presente estudo, alterações em dois parâmetros de crescimento microbianos foram consideradas indicativas do efeito dos herbicidas sobre o coeficiente de rendimento microbiano: (i) aumento da duração da fase lag, em função da necessidade da bactéria induzir mecanismos moleculares de tolerância ao estressor e (ii) aumento do tempo de geração (crescimento exponencial), em função do aumento da proporção dos recursos destinados aos custos de manutenção, em detrimento da produção de biomassa celular. Esses dois mecanismos foram testados pela estimativa do tempo da fase lag e do tempo de geração, respectivamente.

Dos quatro herbicidas que reduziram a capacidade de suporte do crescimento de $A$. brasilense em meio DIGs, apenas a mistura [trifloxysulfuron-sodium + ametryn] aumentou a fase lag (Figura 2). De acordo com Gadagi et al. (2004), o aumento da fase lag observado durante a incubação de Azospirillum sp. na presença dos inseticidas endosulfan ou monocrotophos pode ser devido à adaptação das

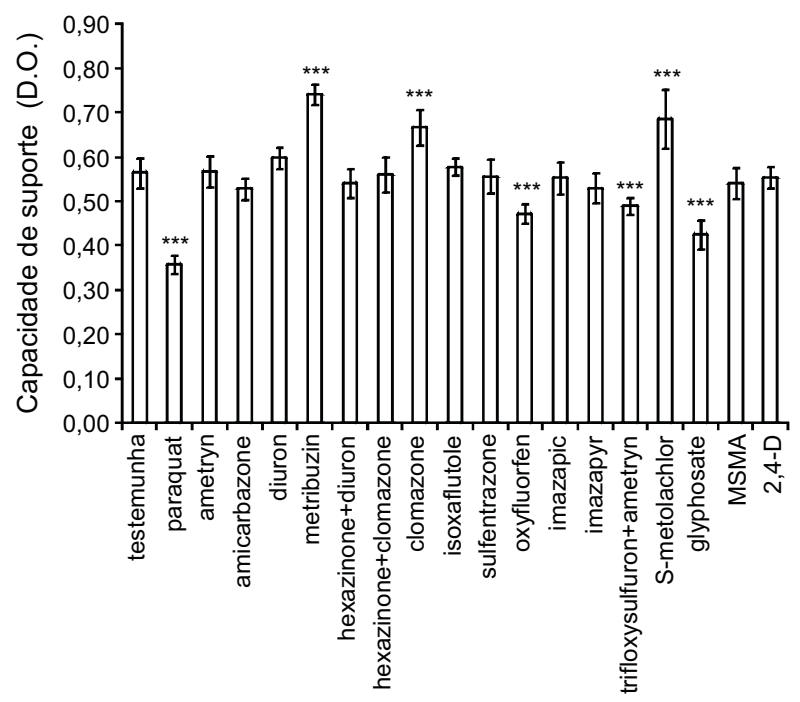

*** Significativo a $0,1 \%$ pelo teste de Dunnett.

Figura 1 - Capacidade de suporte de crescimento de Azospirillum brasilense, mensurado pela densidade ótica $(\mathrm{DO}=450 \mathrm{~nm})$, em meio contendo herbicidas utilizados na cultura da canade-açúcar, nas respectivas doses comerciais. bactérias ao novo ambiente. É importante ressaltar que esse maior tempo de adaptação pode estar associado a um período durante o qual ocorre a indução e a expressão de mecanismos bioquímicos específicos relacionados à tolerância ao herbicida, os quais não são constitutivamente expressos na ausência desse composto. Interessantemente, embora o paraquat tenha diminuído a capacidade de suporte do crescimento de A. brasilense em meio DIGs, esse produto reduziu a fase lag, comparativamente ao controle sem herbicida. Esse decréscimo na duração da fase lag também foi observado para diversos outros herbicidas que não afetaram a capacidade de suporte do meio DIGs quanto ao crescimento de $A$. brasilense, como ametryn, amicarbazone, [hexazinone + diuron], isoxaflutole e imazapic.

Os tratamentos [trifloxysulfuron-sodium + ametryn] e glyphosate reduziram a velocidade de crescimento de $A$. brasilense, o que foi evidenciado pelo aumento dos tempos de geração dessa bactéria para valores médios de 3,52 e $3,58 \mathrm{~h}$, respectivamente (Figura 3 ). O tempo de geração médio para $A$. brasilense em meio DIGs sem herbicidas foi de $2,56 \mathrm{~h}$. Paraquat e oxyfluorfen não afetaram a velocidade de crescimento de $A$. brasilense.

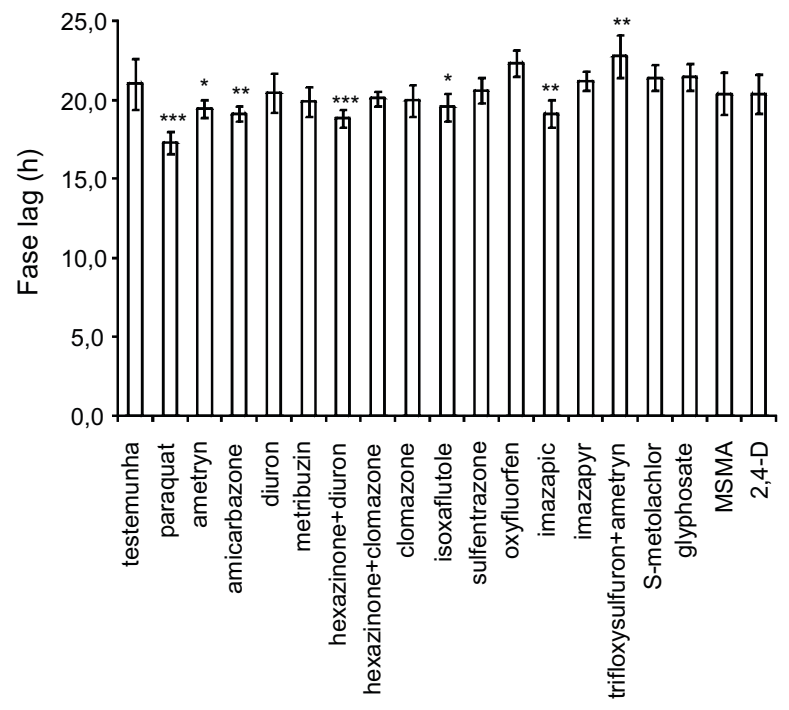

$*, * *, * * *$ Significativo a $5 \%$, a $1 \%$ e a $0,1 \%$ pelo teste de Dunnett, respectivamente.

Figura 2 - Duração da fase lag de Azospirillum brasilense em meio contendo herbicidas utilizados na cultura da cana-deaçúcar. 


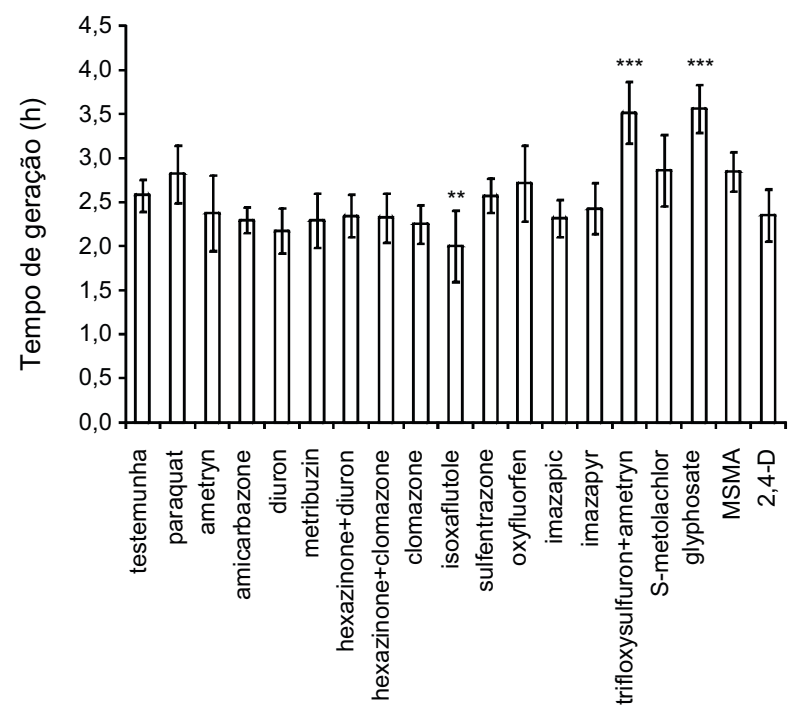

**, *** Significativo a $1 \%$ e a $0,1 \%$ pelo teste de Dunnett, respectivamente

Figura 3 - Tempo de geração de Azospirillum brasilense em meio contendo herbicidas utilizados na cultura da cana-deaçúcar.

É importante observar que os valores de capacidade de suporte de crescimento de A. brasilense dos tratamentos paraquat, oxyfluorfen, [trifloxysulfuron-sodium + ametryn] e glyphosate não se igualaram aos observados no controle, mesmo após um período prolongado de incubação. Isso reforça a hipótese de que os recursos disponiveis no meio de cultura foram menos eficientemente utilizados para o crescimento bacteriano (menor coeficiente de rendimento) na presença desses herbicidas do que nos demais tratamentos. Sugere-se que o menor coeficiente de rendimento de $A$. brasilense na presença de paraquat, oxyfluorfen, [trifloxysulfuronsodium + ametryn] e glyphosate derive do custo energético requerido para manutenção de mecanismos celulares que conferem essa tolerância relativa da bactéria a esses herbicidas. Isoxaflutole reduziu levemente o tempo de geração de A. brasilense, o que acarretou pequeno incremento na taxa de crescimento de A. brasilense. Das \& Debnath (2006) observaram que a aplicação do herbicida oxyfluorfen em solo rizosférico em área cultivada com arroz ocasionou aumento de $42,8 \%$ na população de microrganismos fixadores de $\mathrm{N}$ aeróbios não simbióticos, com consequente aumento de $37,5 \%$ na fixação de N. Segundo Jena et al. (1990), populações de Azotobacter foram estimuladas em áreas de arroz após a aplicação do herbicida thiobencarb.

Os demais herbicidas avaliados no estudo não apresentaram efeito negativo sobre os parâmetros de crescimento, o que está de acordo com o trabalho de Salmeron et al. (1991), que constataram que a adição do herbicida metolachlor ao meio de cultura não alterou o crescimento de Azospirillum brasilense, embora esse herbicida tenha causado efeitos deletérios à atividade da nitrogenase, que desapareceram após 48 h. Também, Nemes-Kósa \& Cserháti (1995) não detectaram nenhum efeito tóxico do herbicida diuron sobre a espécie Azotobacter chroococcum. No entanto, Madhaiyan et al. (2006) observaram que o herbicida 2,4-D reduziu em $50 \%$ o crescimento de G. diazotrophicus quando foi adicionado ao meio na concentração de $22 \mathrm{mg} \mathrm{L}^{-1}$.

Os resultados observados com os herbicidas oxyfluorfen e [trifloxysulfuron-sodium + ametryn] sobre os parâmetros de crescimento não foram regra para todos os herbicidas que possuem mecanismos de ação similares, ou seja, a avaliação de toxicidade deve ser por produto e não pode ser extrapolada ao mecanismo de ação, ou mesmo ao grupo químico.

Os herbicidas MSMA, paraquat e amicarbazone prejudicaram a fixação biológica de nitrogênio (FBN) quando em contato com a bactéria A. brasilense (Figura 4). A magnitude dessas reduções foi severa, principalmente no caso do paraquat, pois foi necessário apenas $1,0 \mathrm{~g} \mathrm{ha}^{-1}$ desse herbicida para que $50 \%$ da FBN fosse inibida, ao passo que, para se obter o mesmo efeito, foram necessários 133,1 $\mathrm{g} \mathrm{ha}^{-1}$ de MSMA (Figura 5). Essas doses estimadas pelas equações de regressão são muito baixas, quando comparadas com a dose normalmente aplicada desses herbicidas nas diversas lavouras brasileiras (paraquat 300 a $600 \mathrm{~g} \mathrm{ha}^{-1}$; MSMA - 1.422 a $2.880 \mathrm{~g} \mathrm{ha}^{-1}$ ). Esses resultados foram obtidos em meio de cultura (in vitro), onde o contato entre os herbicidas e a bactéria diazotrófica é muito estreito. Madhaiyan et al. (2006) reportaram que o herbicida 2,4-D, na sua dose recomendada, ocasionou $59,8 \%$ de redução na atividade de nitrogenase de Gluconacetobacter diazotrophicus, enquanto os herbicidas 


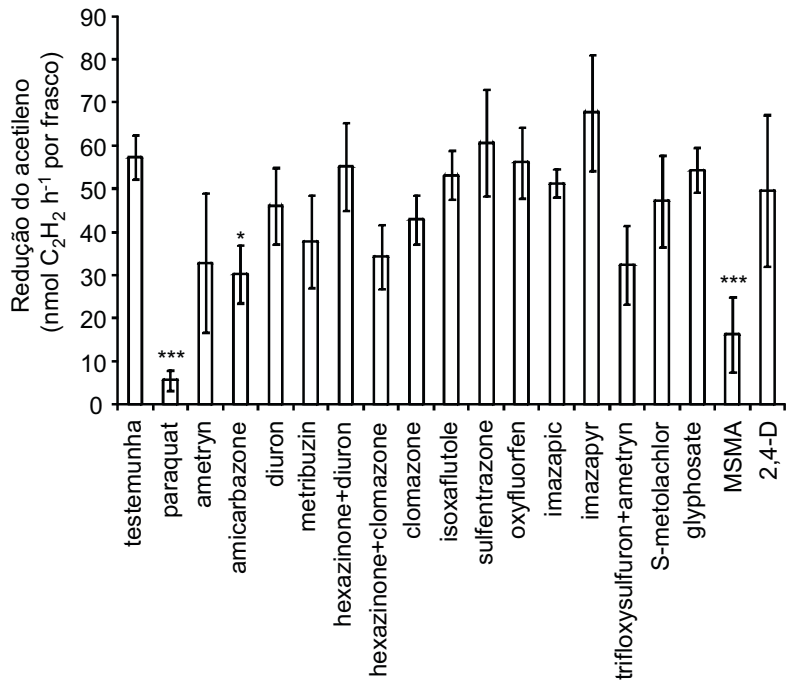

*, *** Significativo a $5 \%$ e a $0,1 \%$ pelo teste de Dunnett, respectivamente.

Figura 4 - Atividade de nitrogenase (redução do acetileno a etileno) por Azospirillum brasilense na presença de herbicidas utilizados na cultura da cana-de-açúcar.

butachlor, alachlor e atrazine inibiram a atividade de nitrogenase dessas bactérias em $22,8,73,6$ e $65,3 \%$, respectivamente. Patnaik \& Rao (1994) relataram que a exposição de Azospirillum sp. ao herbicida 2,4-D estimulou a fixação de $\mathrm{N}$ e o acúmulo de biomassa dessas bactérias diazotróficas. Esse resultado não corrobora o de Rivarola et al. (1992), que apontaram inibição do crescimento celular de Azospirillum brasilense na presença de concentração acima de $1 \mathrm{mM}$ de 2,4-D. Segundo ainda esse autores, essa inibição foi revertida quando as bactérias foram transferidas para um meio livre do herbicida.

É importante salientar que os dados obtidos no presente trabalho foram decorrentes da utilização dos herbicidas na formulação comercial, ou seja, princípio ativo mais todos os demais ingredientes da formulação, tal qual eles são comercializados e, consequentemente, utilizados na agricultura. Conforme o "Working Group Pesticides and Beneficial Arthropods" of the "International Organization for Biological Control of Noxious Animals and Plants (IOBC), West Palaearctic Regional Section (WPRS)", os estudos de seletividade a organismos não alvo devem ser conduzidos
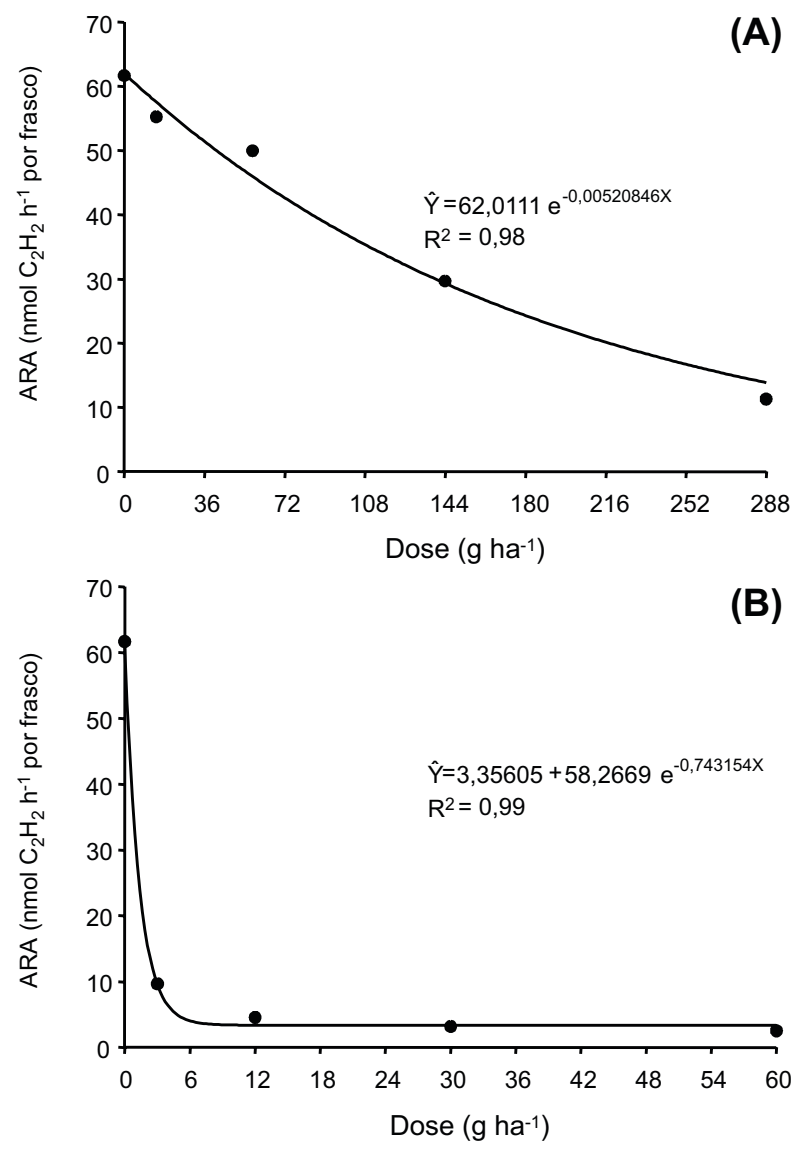

Figura 5 - Atividade da nitrogenase (redução do acetileno a etileno) por Azospirillum brasilense na presença de doses crescentes dos herbicidas MSMA (A) e paraquat (B). Dose de MSMA que inibe a atividade de nitrogenase da bactéria em $50 \%=133,1 \mathrm{~g} \mathrm{ha}^{-1}$. Dose de paraquat que inibe a atividade de nitrogenase da bactéria em $50 \%=1,0 \mathrm{~g} \mathrm{ha}^{-1}$.

com as formulações comerciais (Hassan et al., 2000), pois sabe-se que alguns adjuvantes reduzem a tensão superficial e facilitam a penetração do pesticida. Essa hipótese pode ser confirmada pelos trabalhos que avaliaram o crescimento de outras bactérias fixadoras de $\mathrm{N}$ sob efeito de diversas formulações comerciais do herbicida glyphosate, uma vez que os resultados variaram desde a insensibilidade da bactéria à completa falta de crescimento, em função do produto testado (Santos et al., 2004, 2005a).

Ainda sobre formulações comerciais, segundo Malkones (2000), os aditivos podem afetar os microrganismos e, em certos casos, até modificar o efeito do agroquímico. Para 
Kishinevsky et al. (1988), é possível que solventes, surfatantes e agentes molhantes presentes nas formulações comerciais de pesticidas contribuam para os efeitos inibitórios desses produtos no crescimento de rizóbios um outro grupo de bactérias fixadoras de N. Haahtela et al. (1988) também testaram o glyphosate puro e na formulação comercial Roundup ${ }^{\circledR}$ sobre vários microrganismos e observaram que as concentrações entre $25 \mathrm{e}$ $100 \mu \mathrm{g} \mathrm{L}^{-1}$ alteraram significativamente o crescimento de bactérias do gênero Enterobacter; entretanto, houve maior intoxicação quando elas foram tratadas com a formulação comercial na maior concentração. Berner et al. (1991) mencionaram que aplicações de glyphosate, em formulações com ou sem surfatante, inibiram o crescimento micelial de Calonectria crotalariae.

Em campo, provavelmente, o contato entre A. brasilense e os herbicidas MSMA e paraquat deverá ser muito pequeno, pois esses herbicidas, normalmente, não são aplicados diretamente sobre as plantas de cana-de-açúcar, por não apresentarem seletividade satisfatória a essa cultura, com exceção de algumas aplicações emergenciais de MSMA, quando as plantas daninhas ultrapassam o estádio inicial de desenvolvimento. Ressalta-se também que esses dois xenobióticos (MSMA e paraquat) não apresentam atividade no solo, não havendo portanto a possibilidade de serem absorvidos pelas raízes das plantas de cana-de-açúcar e, assim, entrarem em contato com as bactérias que estão colonizando o interior da planta. Esse comportamento é diferente daquele do amicarbazone, que apresenta boa seletividade às plantas de cana-de-açúcar, podendo ser aplicado sob suas folhagens, e também atividade prolongada no solo - fatores que favorecem a absorção do produto pelas plantas de canade-açúcar e, consequentemente, seu contato com as bactérias diazotróficas. É importante ressaltar que ensaios de campo são necessários para avaliar se esses herbicidas podem prejudicar a ação das bactérias diazotróficas presentes no inoculante que será lançado para uso na cultura da cana-de-açúcar. Testes in vitro mantêm o microrganismo exposto ao máximo ao produto fitossanitário, o que não ocorre em campo, já que há fatores externos que agem sobre o produto, principalmente radiação solar, deriva e ventos, amenizando a ação do princípio ativo (Cavalcanti et al., 2002). Dessa forma, espera-se que produtos considerados compativeis nesse tipo de teste também o sejam quando aplicados em campo.

O glyphosate e a mistura [trifloxysulfuron + ametryn] reduzem a velocidade de crescimento (maiores tempos de geração) de A. brasilense, enquanto MSMA, paraquat $\mathrm{e}$ amicarbazone afetam negativamente a FBN dessa bactéria. Todavia, o impacto negativo sobre a FBN é especialmente drástico na presença do paraquat. Os demais herbicidas utilizados na cultura da cana-de-açúcar e testados neste estudo apresentam alta seletividade a $A$. brasilense, não alterando o crescimento e a atividade de FBN dessa bactéria.

\section{LITERATURA CITADA}

ARRUDA, J. S.; LOPES, N. F.; MOURA, A. B. Behavior of Bradyrhizobium japonicum strains under different herbicide concentrations. Planta Daninha, v. 19, n. 1, p. 111-117, 2001.

BALDANI, J. I. et al. A brief story of nitrogen fixation in sugarcane - reasons for success in Brazil. Func. Plant Biol., v. 29, n. 4, p. $417-423,2002$

BERNER, D. K.; BERGGREN, G. T.; SNOW, J. P. Effects of glyphosate on Calonectria crotalariae and red crown rot of soybean. Plant Dis., v. 75, n. 8, p. 809-813, 1991.

BODDEY, R. M. et al. Use of ${ }^{15} \mathrm{~N}$ natural abundance technique for the quantification of the contribution of $\mathrm{N}_{2}$ fixation to sugar cane and others grasses. Aust. J. Plant Physiol., v. 28, n. 9, p. 889-895, 2001

CAVALCANTI, R. S. et al. Efeito dos produtos fitossanitários fenpropatrina, imidacloprid, iprodione e tiametoxam sobre o desenvolvimento do fungo Beauveria bassiana (Bals.) Vuill. Arq. Inst. Biol., v. 69, n. 1, p. 17-22, 2002.

COELHO, C. H. M. et al. Identificação de genótipos de canade-açúcar quanto ao potencial de contribuição da fixação biológica de nitrogênio. Agronomia, v. 37, n. 1, p. 37-40, 2003.

DAS, A. C.; DEBNATH, A. Effect of systemic herbicides on $\mathrm{N}_{2}$-fixing and phosphate solubilizing microorganisms in relation to availability of nitrogen and phosphorus in paddy soils of West Bengal. Chemosphere, v. 65, n. 6, p. $1082-1086,2006$ 
DÖBEREINER, J.; BALDANI, V. L. D.; BALDANI, J. I. Como isolar e identificar bactérias diazotróficas de plantas não-leguminosas. Brasília: Embrapa - SPI; Itaguaí: Embrapa - CNPAB, 1995. 60 p.

GADAGI. R. S.; TONGMIN, S.; CHUNG, J. B. Chemical insecticide effects on growth and nitrogenase activity of Azospirillum sp. OAD-2. Comm. Soil Sci. Plant Anal., v. 35 , n. $3-4$, p. $495-503,2004$.

HAAHTELA, K.; KILPI, S.; KARI, K. Effects of phenoxy acid herbicides and glyphosate on nitrogenase activity (acetylene reduction) in root-associated Azospirillum, Enterobacter and Klebsiella. FEMS Microbiol. Lett., v. 53, n. $3-4$, p. $123-127,1988$

HAAHTELA, K. et al. Root-associated $\mathrm{N}_{2}$ fixation (acetylene reduction) by Enterobacteriaceae and Azospirillum strains in cold-climate spodosols. Appl. Environ. Microbiol., v. 41, n. 1, p. 203-206, 1981.

HASSAN, S. A. et al. A laboratory method to evaluate the side effects of plant protection products on Trichogramma cacoeciae Marchal (Hym., Trichogrammatidae). In: CANDOLFI, M. P. et al. (Eds.) Guidelines to evaluate side-effects of plant protection products to non-target arthropods. Reinheim: IOBC/WPRS, 2000. p. 107-119.

\section{INSTITUTO BRASILEIRO DE GEOGRAFIA E}

ESTATÍSTICA - IBGE. Levantamento sistemátichttp:// www.ibge.gov.br/home/estatistica/indicadores/agropecuaria/ 1spa/lspa_201101_1.shtm > . Acesso em: 28 fev. 2011.

JENA, P. K.; ADHYA, T. K.; RAO, V. R. Nitrogen fixing bacterial populations as influenced by butachlor and thiobencarb in rice soils. Zentbl. Mikrobiol., v. 145, n. 6, p. $457-60,1990$

KISHINEVSKY, B. et al. Effects of some commercial herbicides on rhizobia and their symbiosis with peanuts. Weed Res., v. 28, n. 4, p. 291-296, 1988

MADHAIYAN, M. et al. Influence of pesticides on the growth rate and plant-growth promoting traits of Gluconacetobacter diazotrophicus. Pestic. Biochem. Physiol., v. 84, n. 2, p. 143-154, 2006.

MALKONES, H. P. Comparison of the effects of differently formulated herbicides on soil microbial activities - a review. J. Plant Dis. Protect., v. 8, n. 8, p. 781-789, 2000.

BRASIL. Ministério da Agricultura, Pecuária e Abastecimento. Agrofit - Consulta de ingrediente ativo. Disponível em: $<$ http://extranet.agricultura.gov.br/ agrofit_cons/principal_agrofit_cons $>$. Acesso em: $28 \mathrm{fev}$. 2011.
MARENCO, R.; LOPES, N. F.; MOSQUIM, P. R. Nodulation and nitrogen fixation in soybeans treated with herbicides. R. Bras. Fisiol. Veg., v. 5, n. 1, p. 121-126, 1993.

MOUTIA, J. F. et al. Plant growth promotion by Azospirillum sp. in sugarcane is influenced by genotype and drought stress. Plant Soil, v. 337, n. 1-2, p. 233-242, 2010.

NASSAR, A. M. et al. Prospects of the sugarcane expansion in Brazil: Impacts on direct and indirect landuse changes. In: ZUURBIER, P.; van de VOOREN, J. (Eds.). Sugarcane ethanol: contributions to change mitigation and the environment. Wageningen: Wageningen Academic Publishers, 2008. p. $63-93$

NEMES-KÓSA, S.; CSERHÁTI, T. Quantitative structureactivity relationship study on the inhibitory effect of some herbicides on the growth of soil micro-organisms. J. Appl. Bacteriol., v. 79, n. 5, p. 483-491, 1995.

NOVO, M. C. S. S. et al. Efeito de linuron e oryzalin no crescimento da planta, na fixação simbiótica do nitrogênio e na produtividade da soja. Planta Daninha, v. 14, n. 1, p. 65-81, 1996.

NOVO, M. C. S. S. et al. Influência de herbicidas aplicados em condições de pós-emergência no crescimento da planta e fixação simbiótica do nitrogênio na cultura do amendoim. Sci. Agric., v. 55, n. 2, p. 276-284, 1998.

OLIVEIRA, A. L. M. et al. The effect of inoculating endophitic $\mathrm{N}_{2}$-fixing bacteria on micropropagated sugarcane plants. Plant Soil, v. 242, n. 2, p. 205-215, 2002

PATNAIK, G. K.; RAO, R. Influence of ammonium and 2,4-dichlorofhenoxy acetic acid on nitrogenase activity in Azospirillum species from rice rhizosphere. Microbios, v. 80, n. 1, p. 17-22, 1994

REIS, V. M. et al. Biological dinitrogen fixation in gramineae and palm trees. Crit. Rev. Plant Sci., v. 19, n. 3, p.227-247, 2000 .

RIVAROLA, V. et al. In vitro protein synthesis is affected by the herbicide 2,4-dichlorophenoxyacetic acid in Azospirillum brasilense. Toxicology, v. 73, n. 1, p. 71-79, 1992.

RODELAS, B. et al. Production of vitamins by Azospirillum brasilense in chemically-defined media. Plant Soil, v. 153, n. 1, p. 97-101, 1993.

RUDORFF, B. F. T. et al. Studies on the rapid expansion of sugarcane for ethanol production in São Paulo State (Brazil) using landsat data. Remote Sens., v. 2, n. 4, p. 1057-1076, 2010 . 
SALMERON, V:; MARTINEZ-TOLEDO, M. V.; GONZALEZ-LOPEZ, J. Effects of alachlor and metolachlor on the biological activity of Azospirillum brasilense grown in chemically defined and dialyzedsoil media. Environ. Toxicol. Chem., v. 10, n. 4, p. 493-499, 1991.

SAMPAIO, E. V. S. B.; SALCEDO, I. H.; BETTANY, J. Dinâmica de nutrientes em cana-de-açúcar. I-Eficiência na utilização de uréia $\left({ }^{15} \mathrm{~N}\right)$ em aplicação única ou parcelada.

Pesq. Agropec. Bras., v. 19, n. 8, p. 943-949, 1984.

SANTOS, A.; FLORES, M. Effects of glyphosate on nitrogen fixation of free-living heterotrophic bacteria. Lett. Appl.

Microbiol., v. 20, n. 6, p. 349-352, 1995.

SANTOS, J. B. et al. Efeitos de diferentes formulações comerciais de glyphosate sobre estirpes de Bradyrhizobium. Planta Daninha, v. 22, p. 293-299, 2004.
SANTOS, J. B. et al. Tolerance of Bradyrhizobium strains to glyphosate formulations. Crop Protec., v. 24, n. 6, p. 543$547,2005 \mathrm{a}$

SANTOS, J. B. et al. Atividade microbiana do solo após aplicação de herbicida em sistemas de plantio direto e convencional. Planta Daninha, v. 23, n. 4, p. 683-691, $2005 b$.

SCHIMEL, J. P.; BALSER, T. C.; WALLENSTEIN, M. Microbial stress-response physiology and its implications for ecosystem function. Ecology, v. 88, n. 6, p. 1386-1394, 2007.

URQUIAGA, S.; CRUZ, K. H. S.; BODDEY, R. M. Contribution of nitrogen fixation to sugar cane: nitrogen-15 and nitrogen balance estimates. Soil Sci. Soc. Am. J., v. 56, n. 1, p. 105-114, 1992. 